Research Article

\title{
Molecular characterization of Indian pathotypes of Puccinia striiformis f. sp. tritici and multigene phylogenetic analysis to establish inter- and intraspecific relationships
}

\author{
Rashmi Aggarwal $^{1}$ (D), Deepika Kulshreshtha ${ }^{1}$, Sapna Sharma ${ }^{1}$, Vaibhav K. Singh ${ }^{1}$, Channappa Manjunatha ${ }^{2}$, \\ Subhash C. Bhardwaj ${ }^{3}$ and Mahender S. Saharan ${ }^{1}$ \\ ${ }^{I}$ Fungal Molecular Biology Laboratory, Division of Plant Pathology, Indian Agricultural Research Institute, \\ New Delhi, India. \\ ${ }^{2}$ ICAR-Indian Agricultural Research Institute, Regional Station Wellington, Tamilnadu, India. \\ ${ }^{3}$ Indian Institute of Wheat and Barley Research, Regional Station, Flowerdale, Shimla, Himachal Pradesh, \\ India.
}

\begin{abstract}
Stripe rust caused by Puccinia striiformis f. sp. tritici (Pst) is one of the most devastating diseases of wheat (Triticum spp.) worldwide. Indian isolates were characterised based on their phenotypic reaction on differential hosts carrying different $Y$ rgenes. Based on virulence/avirulence structure, isolates were characterised into ten different pathotypes viz. 70S0-2, 67S64, 70S4, 66S0, 70S64, 66S64-1, 38S102, 47S102, 46S119, and 78S84. These Indian pathotypes of $P$. striiformis f. sp. tritici and 38 pathotypes of other rust species ( $P$. graminis tritici and $P$. triticina) were used in this study to analyze their molecular phylogenetic relationship. The nucleotides of rDNA-ITS, partial $\beta$-tubulin and ketopantoate reductase genes of all the pathotypes were sequenced directly after PCR. Based on sequence data of rDNA-ITS and $\beta$-tubulin, three phylogenetic groups corresponding to three different species of Puccinia were obtained. Asian isolates formed a distinct evolutionary lineage than from those derived from USA. The sequence similarity of Indian pathotypes with other Asian (China and Iran) isolates indicated the same origin of pathotypes. The results will allow rapid identification of Indian P.striiformis f. sp. tritici pathotypes causing stripe rust in wheat, assist in making predictions regarding potential rust pathotypes, and identifying sources of resistance to the disease in advance.
\end{abstract}

Keywords: Wheat, stripe rust, virulence, diversity, phylogeny.

Received: June 07, 2017; Accepted: December 12, 2017.

\section{Introduction}

Wheat is one of the most important cereal crops in the world and serves as staple food for billions of people. It is the second major cereal crop after rice both in area of production and consumption, and plays a vital role in food and nutritional security. Rusts are among the most widespread and economically important diseases of cereal crops (Roelfs et al., 1992). These obligate parasites are highly specialized and unveil significant variation in the pathogen population (Singh et al., 2008). Mehta (1941) reported economic losses due to rusts up to Rs. 60 million annually and Prasada (1965) estimated losses of Rs. 392 million in India. The requirement of wheat production in the year 2050 is projected at 120 million tons considering its growing de-

Send correspondence to Rashmi Aggarwal. Fungal Molecular Biology Laboratory, Division of Plant Pathology, Indian Agricultural Research Institute, New Delhi, PIN 110012, India. E-mail: rashmi.aggarwal2@gmail.com mand for consumption and trade due to bursting population (Singh et al., 2014). Stripe rust is the most damaging and important disease challenging wheat production worldwide including India (Wellings, 2011). The most serious constraint to protect yield and productivity enhancement that has emerged in the last few years is stripe rust (yellow rust) susceptibility of commercially available wheat cultivars.

Stripe rust in wheat is caused by Puccinia striiformis f.sp. tritici (Pst) and it is present in most wheat-growing regions of the world. In some cases, if infection occurs at early stage and weather remains favorable up to adult stage, stripe rust can cause up to $100 \%$ loss (Syed et al., 2007). It is thought that long-distance dispersal by wind might play a key role in the dissemination of the disease. Widespread occurrence of stripe rust was observed in sub-mountainous districts of Punjab on the widely cultivated wheat variety PBW343 during 2008-09 and the disease was as high as 60 $-80 \%$ resulting in drastic reduction in yield and replacement of this cultivar. During 2010-2011, stripe rust ap- 
peared in severe form in plain areas in Jammu \&Kashmir, foot hills of Punjab and Himachal Pradesh, parts of Haryana, and tarai regions of Uttarakhand (Sharma and Saharan, 2011).

Recently, stripe rust has gained importance in India particularly in North Western Plain Zone (NWPZ) and Northern Hills Zone (NHZ) (Prashar et al., 2007; Saharan et al., 2013). During 2008, the disease occurred in moderate to severe form in Punjab and caused losses of approximately Rs $236 \times 10^{7}$ (Jindal et al., 2012). P. striiformis $\mathrm{f}$. sp. tritici was commonly assumed to have a macrocyclic lifecycle but with missing pycnial and aecial stages until very recently when it was shown to be able to infect some Berberis species (Jin et al., 2010). Under natural conditions, the role of sexual reproduction in the evolution of the pathogen in the US Pacific Northwest and India is limited (Wang et al., 2015), as Berberis role is not ascertained. More than 140 races of Puccinia striiformis $\mathrm{f}$. sp. tritici have been identified in the US and a total of 28 pathotypes have been reported in India (Line and Qayoum, 1992; Chen et al., 2010; Tomar et al., 2014; Bhardwaj et al., 2014). Genetic resistance, i.e. growing resistant cultivars through deployment of stripe rust resistance genes ( $\mathrm{Yr}$ gene), is the most economical, effective and environmentally friendly approach to control the disease (Wellings, 2011). The existence of a large number of pathotypes/races shows the rapid evolution of the pathogen virulence and selections by host crop cultivars with various resistance genes. This continued evolution of rust pathogens against known resistant sources resulted in several yellow rust resistance genes in wheat since 1966; until now, more than 70 catalogued genes have been identified (Talha et al., 2016; Chen and Kang 2017). The predominance of Pst races with virulence for $\mathrm{Yr} 2$ in the 1970s, $Y r 9$ in the 1990s, and $Y r 27$ in recent years contributed to large regional epidemics and crop losses (Chen, 2005; Wellings, 2010).

The genetic diversity of Pst has been investigated since 1990's using various molecular techniques. For Pst population in US, a high genetic diversity was found among 115 single-spore isolates using the random amplified polymorphic DNA (RAPD) technique (Chen et al., 1993). Later, isolates collected from the south central US since 2000 were found to be genetically distinct from older isolates (collected before 2000) using the amplified fragment length polymorphic (AFLP) technique (Markell and Milus, 2008). More recently, phenotypic and genotypic diversity studies using simple sequence repeat (SSR) markers in relatively small or large stripe rust epidemic regions in Northwest China suggested extensive genetic recombination in the Chinese population (Mboup et al., 2009; Lu et al., 2011). In contrast, relatively low genetic diversities have been reported using AFLP markers for the Australian and European Pst populations as the pathogen appears to be clonal (Hovmøller et al., 2002; Enjalbert et al., 2005; Hovmøller and Justesen 2007). No study has been reported on genetic diversity in Indian races of $P$. striiformis tritici, therefore this study was conducted to analyze evolution and genetic variations of $P$. striiformis tritici pathotypes prevalent in India. Furthermore, genetic diversity at an interspecific level was also studied using multigene sequence analysis.

In this study, nucleotide sequence data for rDNA-ITS regions, partial $\beta$-tubulin, and ketopantoate reductase genes of 10 Pst pathotypes along with isolates of other Puccinia species were analyzed. The first objective was to characterize the Indian pathotypes of Puccinia striiformis tritici and assess the relationship among them. The second objective was to clarify the phylogenetic relationships among three Puccinia species infecting wheat and to investigate whether DNA sequence data support the taxonomic separation of these three species.

\section{Material and Methods}

\section{Collection and maintenance of $P$. striiformis tritici (Pst)}

A large number of wheat samples infected with $P$. striiformis tritici were collected from different wheat growing zones of the country. Single urediniospore cultures were maintained on susceptible genotype 'Agra local' under glass house conditions. Urediniospores were collected on sterilized butter paper and stored at $-40^{\circ} \mathrm{C}$ for further use.

\section{Virulence analysis of Pst isolates}

The single uredinial isolates of different rust samples mentioned above were tested for avirulence/virulence on seedlings of differential hosts having different resistance genes. The differential hosts were grown in $10-\mathrm{cm}$ diameter pots and inoculated at single leaf seedling stage, keeping three replicates per differential per isolate. The inoculation and disease recording was done as per standard procedure (Nagarajan et al., 1983; Bhardwaj et al., 2012).

\section{DNA extraction and template preparation}

DNA was extracted from $100 \mathrm{mg}$ of urediniospores of each pathotype using ZR soil microbe DNA miniprep kit (Zymo research, Irvine, CA, USA) following manufacturer's protocol. The DNA obtained was stored at $-20^{\circ} \mathrm{C}$. One microliter of ribonuclease at $10 \mathrm{mg} / \mathrm{mL}$ was added to the extracted nucleic acid and kept at $4^{\circ} \mathrm{C}$ overnight to completely digest the RNA. DNA was quantified by the Nanodrop spectrophotometer (ND1000, Waltham, MA, USA) and DNA concentration was finally adjusted to 50 $\mathrm{ng} / \mu$ Lfor PCR amplification.

\section{Primer design and PCR amplification}

To determine the phylogenetic relationship among 10 different pathotypes, the primers from the two genes ( $\beta$ tubulin and ketopantoate reductase) along with ITS1- 
5.8S-ITS2 region (Table S1; White et al., 1990) were designed using software Primer3. Primer quality was checked using IDT-oligoanalyser software to check the potential of secondary structures, self primer dimer and hetero primer dimer formation within and between the different primer sets. The PCR assays were performed in $25 \mathrm{~L}$ volume containing $75 \mathrm{ng}$ of genomic DNA of each isolate, $200 \mu \mathrm{m}$ each dNTP, $0.2 \mu \mathrm{M}$ primer, $1.5 \mathrm{mM} \mathrm{MgCl}_{2}$, 2.5 U Taq DNA polymerase, and $1 \mathrm{X} \mathrm{Taq}$ buffer in thermal cycler (Bio-Rad, Hercules, CA, USA) programmed for one cycle of denaturation at $94{ }^{\circ} \mathrm{C}$ for 4 min followed by 35 cycles of denaturation at $94{ }^{\circ} \mathrm{C}$ for $1 \mathrm{~min}$, annealing at $55-62^{\circ} \mathrm{C}$ for $1 \mathrm{~min}$, extension at $72{ }^{\circ} \mathrm{C}$ for $2 \mathrm{~min}$, and final extension at $72{ }^{\circ} \mathrm{C}$ for $7 \mathrm{~min}$.

The amplified products were resolved by electrophoresis in $1.2 \%$ agarose gels run at $80 \mathrm{~V}$ for $2 \mathrm{~h}$ in TAE buffer (1X) and stained with ethidium bromide at $0.5 \mu \mathrm{g} / \mathrm{mL}$. The gels were visualized under UV light and photographed with gel documentation unit (Syngene Inc, Cambridge, UK). PCR fragments were excised from agarose gels and purified using QIAquick gel extraction kit (Qiagen). Amplified products were sequenced by ABI 3100 Genetic analyzer at the Department of Biochemistry, South Campus, Delhi University, India. Sequences were BLAST analysed using NCBI database to check for their specificity.

\section{Data analysis}

For phylogenetic analysis, sequences were manually aligned using Bioedit ver. 7.0.9 (Hall, 1999) to remove ambiguous base and primer sequences. Multiple alignments were performed in ClustalW. The sequences obtained for ketopentaote reductase gene, $\beta$ tubulin gene and the ITS region were trimmed, aligned, and the phylogenetic tree was prepared using the software Mega 6 (Tamura et al., 2013). For a comparison with results from earlier research, rDNA-ITS and $\beta$ tubulin sequence data of $P$. striiformis tritici, $P$. graminis tritici, and $P$. triticina from NCBI GenBank were used in a phylogenetic analysis (Table S2).Two Uromyces sequences of ITS regions and the $\beta$ tubulin from GenBank were used as outgroups in ITS and $\beta$ tubulin phylogenetic analysis. As no sequences were available for the ketopentaote reductase gene of Pgt and Pt, we characterized the Indian pathotypes of Pst only. The reference sequence of Pst was taken from the ketopentaote reductase gene sequences to analyse the phylogenetic evolution of the $P$. striiformis f. sp. tritici pathotypes in India.

The evolutionary history was inferred using the NJ method. All positions containing gaps and missing data were eliminated from the dataset (complete deletion option). The evolutionary distances were computed using the maximum composite likelihood method. The Jaccard similarity matrices were used to perform cluster analyses using the neighbor joining (NJ) procedure. Support for the clusters was evaluated using boot strapping analyses with 1000 iterations. Nonparametric bootstrap (BS) was used to assess support for branching topologies (Felsenstein, 1978). The final trimmed sequences were submitted in NCBI database for accession numbers.

\section{Results}

\section{Virulence behavior}

Virulence analysis of single urediniospore cultures of various samples resolved into 10 pathotypes based on avirulence/virulence behavior on differential hosts (Table 1). Among these 10 pathotypes, predominant pathotypes $78 \mathrm{~S} 84$ and 46S119 were virulent to $\operatorname{Yr} 2, \operatorname{Yr} 6, \operatorname{Yr} 7, \operatorname{Yr} 8, \operatorname{Yr} 9$, Yr17, Yr18, Yr19, Yr21, Yr22, Yr23, Yr25, Yrso and avirulent to $Y r 1, Y r 5, Y r 10, Y r 11, Y r 12, Y r 13, Y r 14, Y r 15$, Yr16, Yr24, Yr26, Yrsk genes. Pathotype 38S102 isolated in 1973 from Nilgiri Hills (SHZ) showed avirulence to $Y r 9$ along with $Y r 1, Y r 3, Y r 5, Y r 10, Y r 11, Y r 12, Y r 13, Y r 14$, $Y r 15, Y r 16, Y r 24, Y r 26, Y r s p, Y r$ sk genes and virulence to $Y r 2, Y r 4, Y r 6, Y r 7, Y r 8, Y r 17, Y r 18, Y r 19, Y r 21, Y r 22$, Yr23, Yr25, YrA genes. Pathotypes 70S0-2, 70S4, 67S64, and 66S0 detected during 1936-37 nearly showed a similar behavior in knocking down R-genes (Table 1).

\section{ITS sequence-based analysis}

A sharp band of about $600 \mathrm{bp}$ was amplified in all the pathotypes taken for the study using ITS specific primers (Figure S1a). In the phylogenetic tree (Figure 1), three main groups could be distinguished: group A, included all pathotypes of P. striiformis; group B was closely related to group A, and included all $P$. graminis tritici isolates in this group, while group $\mathrm{C}$ was distinct from groups $\mathrm{A}$ and $\mathrm{B}$, comprising all $P$. triticina isolates.

Furthermore, Group A was divided into two subgroups (A1 and A2). In subgroup A1 the isolates were from Asian countries (Iran, China, and India), whereas all the isolates of USA were clustered into subgroup A2. In subgroup A1, the two primitive Indian pathotypes 67S64 (1936) and 66S0 (1937) and another pathotype 66S64-1 (1970) were clustered with Iran and Chinese isolates showing the diverse nature of these pathotypes. Pathotype 38S102 and 70S64 were found to be closely related in phylogeny and both these pathotypes originated at the same time in India i.e., 1970.The multiple sequence alignment of all the Indian pathotypes separately for ITS1 (Figure S2) and ITS2 (Figure S3) regions showed that ITS2 region was more conserved than the ITS1. Significant divergence was observed among positions 11-155 within the ITS1 sequences.

The base sequence at 52,123,146, and 150 of ITS1 region separated the old pathotypes (70S0-2, 70S4, 67S64, and 66S0) originated in 1936-37 from the recent ones (46S119 and 78S84), whereas nucleotides at 123 and 146 positions showed variation in presently prevalent pathotypes $46 \mathrm{~S} 119$ and $78 \mathrm{~S} 84$. The 5.8S rRNA gene was found to 


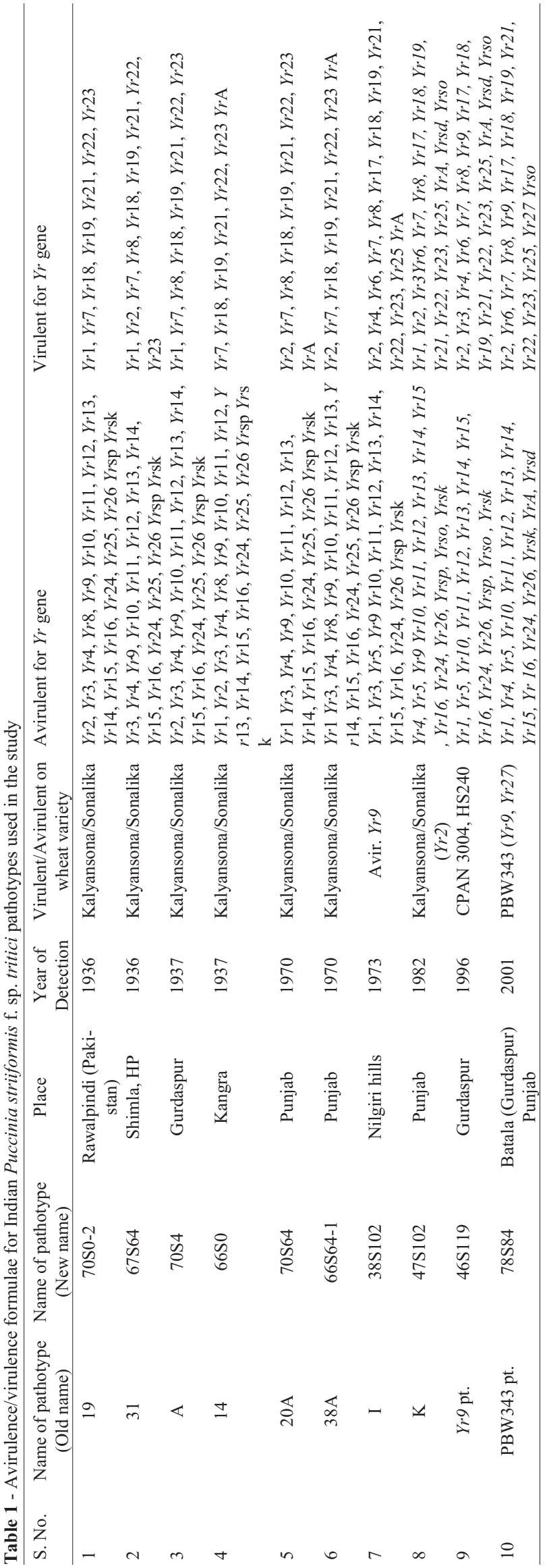

be fully conserved among all the 10 pathotypes. The ITS2 region was also mostly conserved; however, at position 17 and 18, pathotype 38S102 showed nucleotide substitution from AT to TA. Insertion and deletion events were also observed in this region.

Group B included all isolates of $P$. graminis tritici collected from Iran and the US and two subgroups (B1 and B2) could be distinguished. Subgroup B1 included two $P$. graminis tritici sequences from Iran, while US isolates were included in subgroup B2. In group C, two subgroups (C1 and $\mathrm{C} 2$ ) of $P$. triticina were formed; two Pakistani isolates PK-178 and PK-189 also belonged to the same subgroup (C1). Subgroup C2 included all the US isolates except R206 (Belgium) and 104-4 (India).

\section{Ketopantoate reductase gene sequence-based analysis}

A band of $1500 \mathrm{bp}$ was obtained using ketopantoate reductase specific primers (Figure S1b). The phylogenetic analysis of sequences of ketopantoate reductase gene was performed with pathotypes collected from different regions of India. In the phylogeny, pathotype 70S4 detected in year 1937 from Gurdaspur, singly formed a separate cluster (Figure 2), whereas all the remaining pathotypes (70S0-2, 67S64, 66S0, 70S64, 66S64-1, 38S102, 47S102, 46S119, and 78S84) grouped together into a separate major cluster. The major cluster was further subdivided into two sub clusters, wherein the only pathotype PST-130 from Washington, USA used as reference for the ketopantoate reductase phylogeny grouped together with Indian pathotypes. The sequences were very closely related and showed 0.0005 base substitutions/site.

\section{$\beta$-tubulin gene sequence-based analysis}

For $\beta$-tubulin specific primers, the desired band of $957 \mathrm{bp}$ was obtained in all the pathotypes of $P$. striiformis tritici (Figure S1c). Based on $\beta$-tubulin gene sequence analysis of all the pathotypes, two major clusters were formed (Figure 3) showing close similarity between all Pst pathotypes, which were grouped together in same sub cluster while Pt strains were in a separate sub cluster. Overall, the sequences of $\beta$-tubulin gene have changed during the course of evolution and the phylogeny distinguished the three rust fungi viz. Pst, Pgt, and Pt into three separate groups viz, group A, B, and C, respectively. Group A clustered Pst pathotypes and showed that Pathotype 70S4 had sequence homology with the Chinese pathotype (Pst TU5S).The Indian pathotype 78S84 detected in 2001, an old Indian pathotype (66S64-1) detected in the year 1970, and the voucher pathotype of Sydney also clustered together in the same group. Similarly, pathotypes 67S64, $47 \mathrm{~S} 102$, and $46 \mathrm{~S} 119$ were found closely related in the phylogeny. The interspecies analysis of Pst and Pt strains separated the isolates of the two species into separate clusters. 


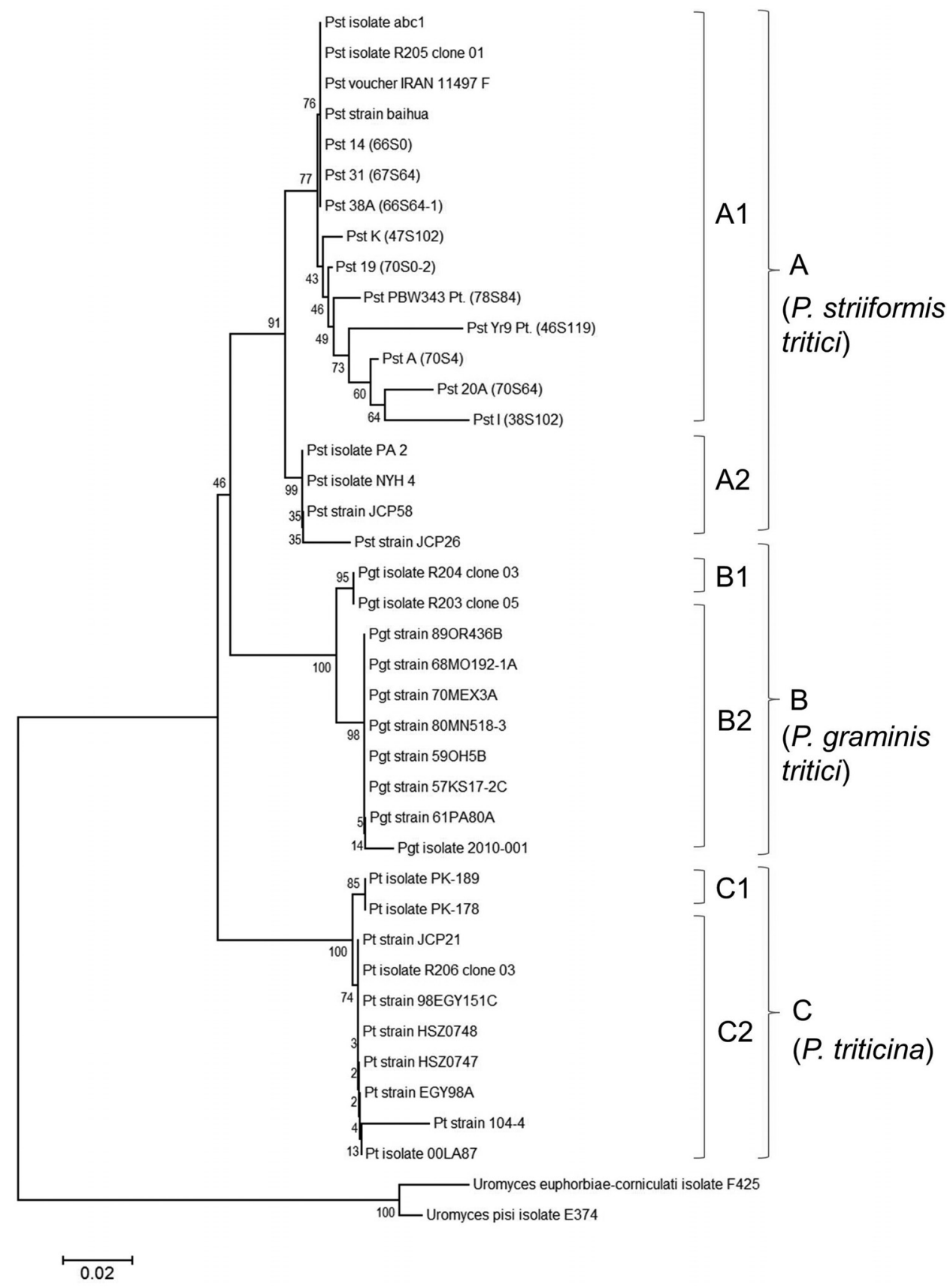

Figure 1 - Neighbor-joining phylogenetic tree based on nucleotide sequence of ITS showing phylogenetic relations among pathotypes of $P$. striiformis tritici, $P$. graminis tritici, and P. triticina.

\section{Multiple gene-based phylogeny using combined rDNA-ITS, partial $\beta$-tubulin, and ketopantoate reductase gene sequences data}

The accession numbers of ITS, partial $\beta$-tubulin, and ketopantoate reductase gene submitted to NCBI database for each pathotype are given in Table 2. A phylogenetic tree was constructed from the combined rDNA-ITS, partial $\beta$-tubulin, and ketopantoate reductase gene sequence data sets of Indian pathotypes (Figure 4). The pathotypes clustered in a manner that showed the evolution of new patho- types from the previously existing ones. Pathotype 38S102 was clustered with pathotype 70S0-2 and pathotype 70S4 with pathotype 70S64.Two clusters were formed, of which cluster A was the major cluster further subdivided into A1 and A2, consisting mostly of $P$. striiformis tritici pathotypes taken for the study.

\section{Discussion}

A revolution in the analysis of plant pathogens diversity came with PCR-based molecular techniques, which has 


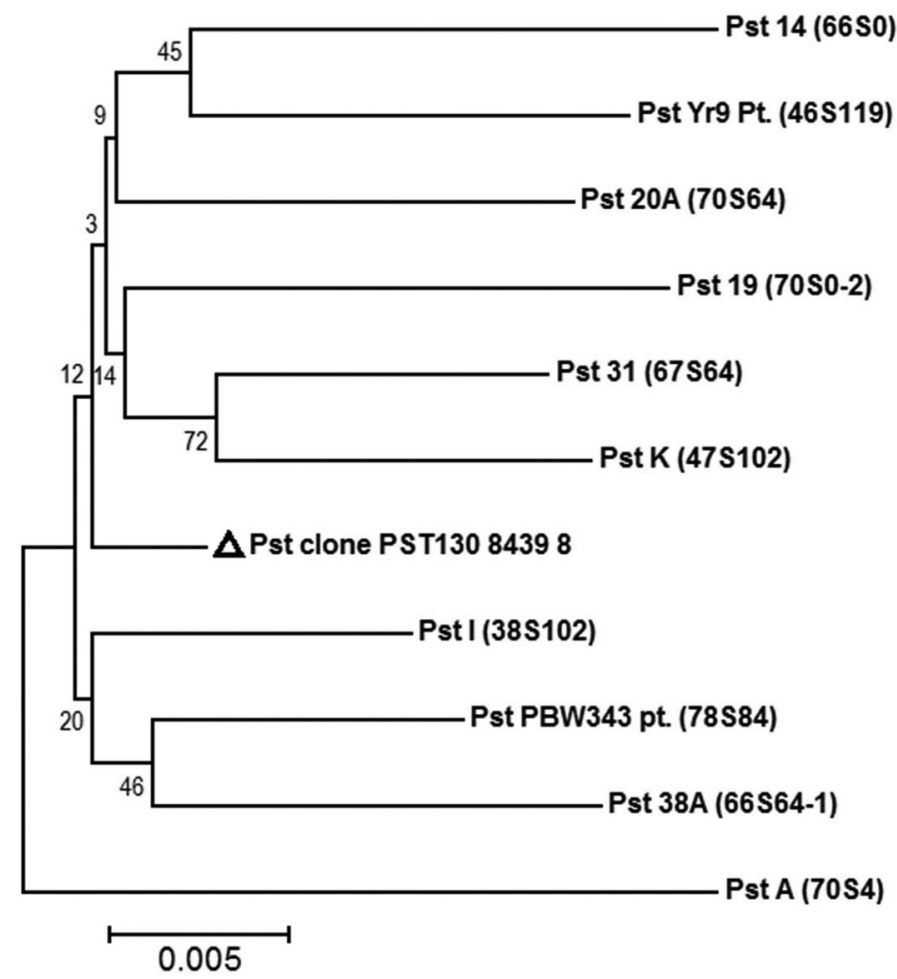

Figure 2 - Neighbor-joining phylogenetic tree based on nucleotide sequence of ketopantoate reductase gene showing phylogenetic relations among $P$. striiformis $\mathrm{f}$. sp. tritici pathotypes.

enhanced the understanding of taxonomy and population structure. Sequence based molecular characterization may help in understanding the genetic structure and relationship

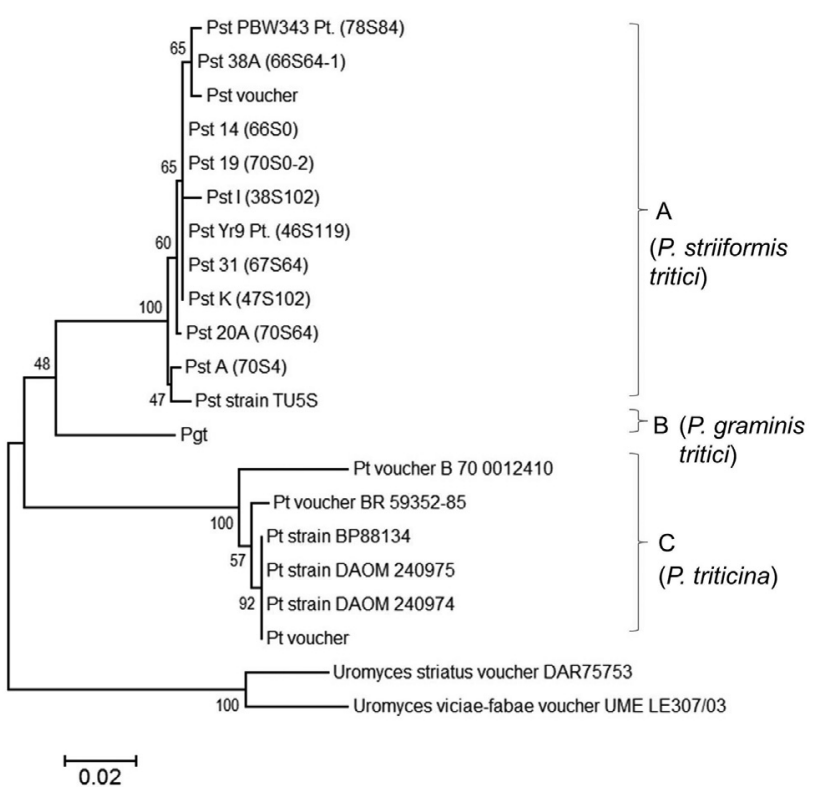

Figure 3 - Neighbor-joining tree based on nucleotide sequence of $\beta$-tubulin showing phylogenetic relations among pathotypes of $P$. striiformis tritici, $P$. graminis tritici, and P.triticina among the races of plant pathogens. It has been reported earlier that genetic variation in populations of rust pathogens are shaped by sexual recombination (Kolmer, 1992), mutation (Park et al., 2002), migration of genetically distinct individuals between and within crop production regions, genetic drift extinction events (Justesen et al., 2002). Furthermore, agricultural practices, such as the cultivation of varieties having different R-genes, promoted the selection of virulent types (Burdon and Silk, 1997).

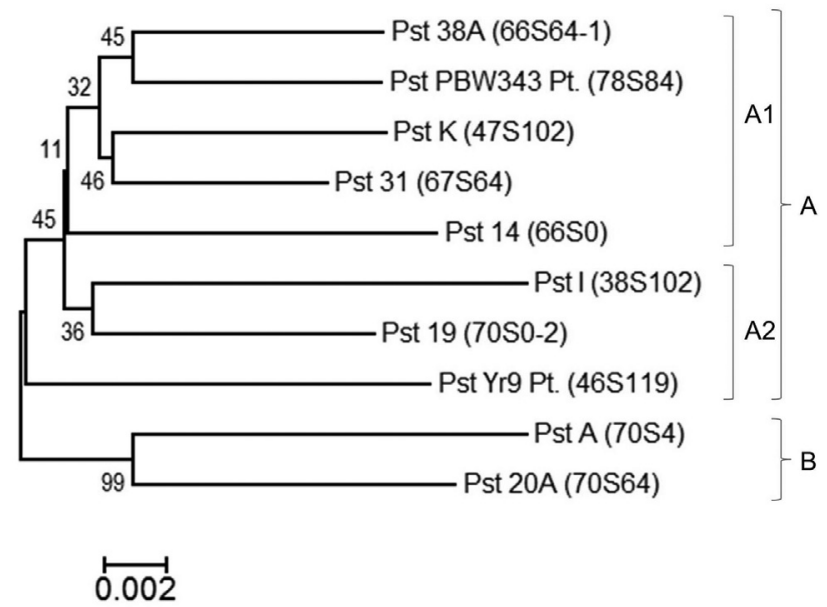

Figure 4 - Neighbor-joining tree based on combined nucleotide sequence of ITS, $\beta$-tubulin, and ketopantoate reductase showing phylogenetic relations among pathotypes of $P$. striiformis tritici. 
Table 2 - Indian Pst pathotype sequences of ITS and $\beta$-tubulin and ketopantoate reductase submitted to NCBI for phylogenetic study.

\begin{tabular}{|c|c|c|c|}
\hline Past Pathotypes & ITS & $\beta$-tubulin & ketopantoate reductase \\
\hline 19 (70S0-2) & KX061103 & KX424983 & KX249826 \\
\hline 31 (67S64) & KT320894 & KX424984 & KX249827 \\
\hline A (70S4) & KT320892 & KX424987 & KX249833 \\
\hline $14(66 \mathrm{~S} 0)$ & KX061104 & KX424982 & KX249825 \\
\hline $20 \mathrm{~A}(70 \mathrm{~S} 64)$ & KT320893 & KX424988 & KX061102 \\
\hline 38A (66S64-1) & KT305926 & KT345695 & KX249832 \\
\hline I (38S102) & KT320895 & KX424981 & KX249830 \\
\hline $\mathrm{K}(47 \mathrm{~S} 102)$ & KT320891 & KT345694 & KX249829 \\
\hline $\operatorname{Yr} 9$ pt. (46S119) & JQ360861 & KX424986 & KX249828 \\
\hline PBW343 pt. (78S84) & JQ360860 & KX424985 & KX249831 \\
\hline
\end{tabular}

Virulence phenotypes have been correlated with the genetic differentiation of Puccinia triticina populations based on SSR variations (Kolmer and Ordoñez, 2007). Cryptic sexual reproduction or gene conversion can also have a drastic effect on the reshuffling of genetic material (Burt et al., 1996; Bengtsson, 2003) resulting in faster spread of virulent genes and emergence of new virulence combinations. In India, sexual reproduction in wheat rust pathogens is not reported so far, therefore new pathotypes originate either through mutation or parasexuality. Early molecular studies provided evidence of genetic distinction of three Puccinia species on wheat, but the phylogenetic relationships among pathotypes belonging to these three species have not been reported and were addressed in this study.

Historically, the use of major race specific resistance $(R)$ genes in wheat varieties has been an effective method for disease management. However, these approaches are hampered by the evolution of resistance-breaking races of Pst. In recent years, concerns over stripe rust have increased with the emergence of new and more aggressive Pst races that have expanded the virulence profiles and are capable of adapting to warmer temperatures compared to most previous races (Hovmøller et al., 2010). For example, the appearance of Pst races that overcome widely deployed $R$ genes (such as $\mathrm{Yr} 2, \mathrm{Yr} 9, \mathrm{Yr} 17$, and $\mathrm{Yr} 27$ ) has led to destructive pandemics (Wellings, 2011). In the present study, inter and intraspecific phylogenetic relationship among Indian pathotypes of Puccinia species infecting wheat has been established based on multigene sequence analysis. The understanding of pathogenicity, avirulence/virulence behavior, and their evolution is critical for the development of more effective breeding strategies and achieve durable resistance.

Molecular analyses were initiated to study the phylogenetic connection and to provide evidence for reassessment of the Puccinia species generic taxonomy. We selected multiple genes to detect genetic variation among $P$. striiformis pathotypes from different regions because this method is technically simple and fast. ITS and $\beta$ -tubulin sequences have been widely used for phylogenetic studies; however, recently, a diagnostic marker has been developed for Pst using ketopantoate reductase gene (Aggarwal et al., 2017). Therefore, we used this gene to analyse the evolutionary relationship among Pst pathotypes.

Based on the ITS sequence analysis, the pathotype 38S102 formed a separate cluster. Position 17 and 18 of ITS2 region might explain the different behavior of this pathotype and separated it from other Pst pathotypes. Similarly, the nucleotide substitution at position 123 and 146 of pathotype 78S84 might explain the virulence of this pathotype for Yr27 (Prashar et al., 2007). Furthermore, the sequence similarity of Indian pathotypes with other Asian (China and Iran) isolates suggests the intrinsic ability of Pst for long distance spore dispersal (Brown and Hovmøller, 2002) and these new races pose an increasing threat to global wheat production and food security (Milus et al., 2009). Our results demonstrated that multigene analysis is useful for detection of genetic variation among $P$. striiformis isolates.

There was considerable sequence variation in the ITS sequences and little or no variation in the regions of the 5.8S rDNA. The sequence variations of ITS reported in the literature are usually higher in ITS1 than ITS2 (Park et al., 2001). Our data showed that the ITS rRNA gene can be used for inferring the phylogeny of closely related species, as well as for examining the relationships between and within the populations of the same species. This may also be helpful for the identification of species that cannot be distinguished using only morphological characteristics, or for testing interbreeding potential. In order to improve the use of the ITS region for diagnostics in fungi, the secondary structure of ITS2 can be used to increase the specificity of ITS spacers (Landis and Gargas, 2007). Whole genome based evolutionary analysis has also been performed previously, which separated Pst pathotypes on the basis of their 
year of detection and geographical region (Kiran et al., 2017).

In our results, the ITS phylogenetic tree best represented all the three fungi in accordance with their detection time and geographical location. However, the phylogenetic tree based on multigene analysis explained the clustering of Pst pathotypes on a broader aspect of their evolution from previously existing pathotypes due to the selection pressure. In the present study, ITS and $\beta$-tubulin sequences separated the three rust fungi of wheat into separate clusters; therefore, these can be used as markers to identify and differentiate this fungus. Earlier, a RAPD and URP-based molecular analysis has been done for predominant Indian pathotypes of all the three rust species infecting wheat (Aggarwal et al., 2018). However, this is the first report of a multigene sequence-based phylogenetic analysis of Pst pathotypes along with $P$. graminis tritici and $P$. triticina.

This study will allow rapid identification of Indian Puccinia striiformis f. sp. tritici pathotypes causing stripe rust in wheat and the resulting phylogeny will assist in making predictions regarding potential rust pathotypes of wheat and identifying sources of disease resistance in advance. Our results indicate the need for more detailed phylogenetic analyses within the Pst clades, which will require the inclusion of additional taxa and loci.

\section{Acknowledgments}

The authors are greatful to the Indian Council of Agricultural Research for funding AMAAS project (NBAIM/AMAAS/2014-15/68) to carry out this work. The authors also thank the ICAR-Indian Institute of Wheat and Barley Research (ICAR-IIWBR), Regional Station Flowerdale Shimla, India for providing the pure inocula of rust pathotypes, and the Director of the ICAR-Indian Agricultural Research Institute, New Delhi for providing the facilities to carry out the research.

\section{References}

Aggarwal R, Sharma S, Gupta S, Banerjee S, Bashyal BM and Bhardwaj SC (2018) Molecular characterization of predominant Indian wheat rust pathotypes using URP and RAPD markers. Indian J Biotechnol 17: 326-335.

Aggarwal R, Sharma S, Gupta S, Manjunatha C, Singh VK and Kulshreshtha D (2017) Gene-based analysis of Puccinia species and development of PCR-based marker to detect Puccinia striiformis f. sp. tritici causing yellow rust of wheat. J Gen Plant Pathol 83:205-215.

Bhardwaj SC, Gangwar OP, Singh SB, Saharan MS and Sharma S (2012) Rust situation and pathotypes of Puccinia species in Leh Leach in relation to recurrence of wheat rusts in India. Indian Phytopath 65:230-32.

Bhardwaj SC, Gangwar OP, Prasad P and Khan H (2014) Mehtaensis 34:1-23.

Brown JKM and Hovmøller MS (2002) Aerial dispersal of pathogens on the global and continental scales and its impact on plant disease. Science 297:537-541.
Burdon JJ and Silk J (1997) Sources and patterns of diversity in plant pathogenic fungi. Phytopathology 87:664-669.

Bengtsson BO (2003) Genetic variation in organisms with sexual and asexual reproduction. J Evol Biol 16:189-199.

Burt A, Carter DA, Koenig GL, White TJ and Taylor JW (1996) Molecular markers reveal cryptic sex in the human pathogen Coccidioides immitis. Proc Natl Acad Sci USA 93:770-773.

Chen X and Kang Z (2017) Stripe rust. Springer, Netherlands, 391 p.

Chen XM (2005) Epidemiology and control of stripe rust [Puccinia striiformisf. sp.tritici] on wheat. Can J Plant Pathol 27:314-337.

Chen XM, Line RF and Leung H (1993) Relationship between virulence variation and DNA polymorphism in Puccinia striiformis. Phytopathology 83:1489-1497.

Chen XM, Penman L, Wan AM and Cheng P (2010) Virulence races of Puccinia striiformis f. sp. tritici in 2006 and 2007 and development of wheat stripe rust and distributions, dynamics, and evolutionary relationships of races from 2000 to 2007 in the United States. Can J Plant Pathol 32:315-323.

Enjalbert J, Duan X, Leconte M, Vautrin D, Hovmøller MS and Vallavieille-Pope C (2005) Genetic evidence of local adaptation of wheat yellow rust (Puccinia striiformis f. sp. tritici) within France. Mol Ecol 14:2065-2073.

Felsenstein J (1978) Cases in which parsimony or compatibility methods will be positively misleading. Syst Zool 27:401-410.

Hall TA (1999) BioEdit: A user-friendly biological sequence alignment editor and analysis program for Windows 95/98/NT. Nucleic Acids Symp Ser 41:95-98.

Hovmøller MS and Justesen AF (2007) Rates of evolution of avirulence phenotypes and DNA markers in a northwest European population of Puccinia striiformis f. sp. tritici. Mol Ecol 16:4637-4647.

Hovmølller MS, Justesen AF and Brown JKM (2002) Clonality and long-distance migration of Puccinia striiformis $\mathrm{f}$. $\mathrm{sp}$. tritici in north-west Europe. Plant Pathol 51:24-32.

Hovmøller MS, Walter S and Justesen AF (2010) Escalating threat of wheat rusts. Science 329:369.

Jin Y, Szabo LJ and Carson M (2010) Century-old mystery of Puccinia striiformis life history solved with the identification of Berberis as an alternate host. Phytopathology 100:432-435.

Jindal MM, Sharma I and Singh BN (2012) Losses due to stripe rust caused by Puccinia striiformis in different varieties of wheat. J Wheat Res 4:33-36.

Justesen AF, Ridout CJ and Hovmøller MS (2002) The recent history of Puccinia striiformis f. sp. tritici in Denmark as revealed by disease incidence and AFLP markers. Plant Pathol 51:13-23.

Kiran K, Rawal HC, Dubey H, Jaswal R, Bhardwaj SC, Prasad P, Pal D, Devanna BN and Sharma TR (2017) Dissection of genomic features and variations of three pathotypes of Puccinia striiformis through whole genome sequencing. Sci Rep 7:42419.

Kolmer JA (1992) Virulence heterozygosity and gametic phase disequilibria in two populations of Puccinia recondita (wheat leaf rust fungus). Heredity 68:505-513.

Kolmer JA and Ordoñez ME (2007) Genetic differentiation of Puccinia triticina populations in Central Asia and the Caucasus. Phytopathology 97:1141-1149. 
Landis FC and Gargas A (2007) Using ITS 2 secondary structure to create species-specific oligonucleotide probes for fungi. Mycologia 99:681-692.

Line RF and Qayoum A (1992) Virulence, aggressiveness, evolution and distribution of races of Puccinia striiformis (the cause of stripe rust of wheat) in North America, 1968-87. US Dept Agric Tech Bull 1788:1-44.

Lu NH, Zhan GM, Chen XM, Wang JF, Huang LL and Kang ZS (2011) Spatial genetic diversity and interregional spread of Puccinia striiformis f. sp. tritici in the Northwest China. Eur J Plant Pathol 131:685-693.

Markell SG and Milus EA (2008) Emergence of a novel population of Puccinia striiformis f. sp. tritici in Eastern United States. Phytopathology 98:632-639.

Mboup M, Leconte M, Gautier A, Wan AM, Chen W, Vallavieille-Pope C and Enjalbert J (2009) Evidence of genetic recombination in wheat yellow rust populations of a Chinese over-summering area. Fungal Genet Biol 46:299-307.

Mehta KC (1941) The wheat rust problem in India. Curr Sci 10:357-361.

Milus EA, Kristensen K and Hovmøller MS (2009) Evidence for increased aggressiveness in a recent widespread strain of Puccinia striiformis f. sp. tritici causing stripe rust of wheat. Phytopathology 99:89-94.

Nagarajan S, Nayar SK and Bahadur P (1983) The proposed brown rust of wheat (Puccinia recondita f. sp. tritici) virulence analysis system. Curr Sci 52:413-416.

Park JE, Kim GY, Park HS, Nam BH, An WG, Cha JH, Lee TH and Lee DJ (2001) Phylogenetic analysis of caterpillar fungi by comparing ITS 1-5.8S-ITS 2 ribosomal DNA sequences. Mycobiology 29:121-131.

Park RF, Bariana HS, Wellings CR and Wallwork H (2002) Detection and occurrence of a new pathotype of Puccinia triticina with virulence for Lr24 in Australia. Aust J Agric Res 53:1069-1076.

Prasada KR (1965) Our elusive fungal foes. In: Indian Science Congress Association, Calcutta.

Prashar M, Bhardwaj SC, Jain SK and Dutta D (2007) Pathotypic evolution in Puccinia striiformis in India during 1995-2004. Aust J Agric Res 58:602-604.

Roelfs AP, Singh RP and Saari EE (1992) Rust diseases of wheat: Concepts and methods of disease management. CIMMYT, Mexico, 81 p.

Saharan MS, Selvakumar R and Sharma I (2013) Wheat Crop Health Newsletter 18:1-8.

Sharma I and Saharan MS (2011) Status of wheat diseases in India with a special reference to stripe rust. Pl Dis Res 26:156209 .
Singh RP, Hodson DP, Huerta-Espino J, Jin Y, Njau P, Wanyera R, Herrera-Foessel SA and Ward RW (2008) Will stem rust destroy the world's wheat crop? Adv Agron 98:271-309.

Singh SK, Tiwari V and Sharma I (2014) Indian wheat programme as backbone for national food security. In: $3^{\text {rd }}$ International conference on Agriculture \& Horticulture, Hyderabad, p. 34.

Syed NA, Haque ML, Ahmedani MS, Samina B and Rattu AR (2007) Assessment of yield losses caused by Puccinia striiformis triggering stripe rust in the most common wheat varieties. Pak J Bot 39:2127-2134.

Talha M, Swati, Harsha and Jaiswal JP (2016) Marker assisted detection of underutilized potential $\mathrm{Yr}$ genes in elite wheat breeding lines. SABRAO J Breed Genet 48:309-317.

Tamura K., Stecher G, Peterson D, Filipski A and Kumar S (2013) MEGA6: Molecular Evolutionary Genetics Analysis Version 6.0. Mol Biol Evol 28:2731-2739.

Tomar SMS, Singh SK, Sivasamy M and Vinod (2014) Wheat rusts in India: Resistance breeding and gene deployment - A review. Indian J Genet Plant Breed 74:129-156.

Wang MN, Wan AM and Chen XM (2015) Barberry is more important as an alternate host for stem rust than for stripe rust in the US Pacific Northwest. P1 Dis 99:1507-1516.

Wellings C (2010) Global status of stripe rust. In: Borlaug Global Rust Initiative 2010 Technical Workshop, Saint Petersburg, p. 34 .

Wellings CR (2011) Global status of stripe rust: A review of historical and current threats. Euphytica 179:129-141.

White TJ, Bruns T, Lee S and Taylor J (1990) Amplification and direct sequencing of fungal ribosomal RNA genes for phylogenetics. In: Innis MA, Gelfand DH, Shinsky JJ and White JJ (eds) PCR protocols: a guide to methods and applications, Academic Press, New York, p. 315-322.

\section{Supplementary Material}

The following online material is available for this article: Figure S1 - Agarose gel showing amplified products.

Figure S2 - Multiple sequence alignment of internal transcribed spacer 1.

Figure S3 - Multiple sequence alignment of internal transcribed spacer 2.

Table S1 - Details of genes and primers.

Table S2 - NCBI sequences of ITS, $\beta$-tubulin, and ketopantoate reductase

\section{Associate Editor: Célia Maria de Almeida Soares}

License information: This is an open-access article distributed under the terms of the Creative Commons Attribution License (type CC-BY), which permits unrestricted use, distribution and reproduction in any medium, provided the original article is properly cited. 